\title{
Agent-based Simulation of the Railway Connection from and to the Vienna I nternational Airport
}

\author{
Matthias Obermair², Barbara Glock ${ }^{1 *}$ \\ ${ }^{1}$ dwh GmbH, Simulation Services, Neustiftgasse 57-59, 1070 Vienna, Austria; * barbara.glock@dwh.at \\ ${ }^{2}$ Vienna Univ. of Technology, Inst. of Analysis and Scientific Computing, Karlsplatz 13, 1040 Vienna, Austria;
}

Simulation Notes Europe SNE 24(3-4), 2014, 123 - 126 DOI: $10.11128 /$ sne.24.sn. 10253

Received: March 25, 2014; Revised September 10, 2014; Accepted: October 20, 2014;

Abstract. This agent-based simulation deals with the railway connection of the Vienna International Airport and was created using the simulation program AnyLogic. With this program a transportation company should be able to estimate easily which timetable allows to transport a maximum of passengers without the use of too many trains.

\section{I ntroduction}

The Vienna International Airport is located in the centre of Europe. This makes the airport an important platform for international air travelling especially in Central and Eastern Europe. In 2013 arou nd $22 \mathrm{~m}$ illion passengers were transported. There are more than 15 million people who need to be transported to the airport. Additionally the airport staff uses the different transportation possibilities as well [1].

This simulation investigates and simulates the railway connecti on of the airport usi ng the Java-base d simulation program AnyLogic.

Depending on various parameters that mostly can be changed by the user, this m odel offers a simplified presentation of a pa ssenger movement at the airport between gates and railway st ation. Moreover the trai ns of the Viennese S-Ba hn a nd the City Airport Train (CAT) are simulated. These trains are created according to the original timetable, but the amount of trains can be increased by the user, which leads to a shorter tim e interval of the trains during rush hours. Furthermore the expenses, income and profit of the railway companies are calculated as well.

\section{The Model}

There are ni ne types of agents re presenting di fferent types of passengers and different types of trains:

- Incoming economy/business travelers

- Outgoing economy/business travelers

- Passengers who do not use a train for airport transportation

- Incoming S-Bahn/CAT trains

- Outgoing S-Bahn/CAT trains

This amount of different agents is necessary because all of them have different goals and feat ures. They will be described in later on in much more detail.

The parameters that are variable are:

- Percentage of train travelling passengers

- Percentage of S-Bahn travelling passengers

- Percentage of passengers who only have hand luggage

- Walking speed of passengers

- Capacity of the trains

- Ticket price

- Working expenses

Passenger pa rameters are se parated into e conomy and business, train parameters into S-Bahn and CAT. There is also the possibility to add an arbitrary am ount of additional trai ns for each $t r$ ain provider during a ti me interval which can be inserted too.

The environment in which the agents act and interact is a sim plified illustration of the airport $\mathrm{i}$ ncluding its railway station and rails, c heck-in, baggage claim area and the main exit as show $n$ in Figure 1. The passenger representing agents are moving in this environment. The other agents, who represent the trains are moving along the railways that are attached to the railway station. 


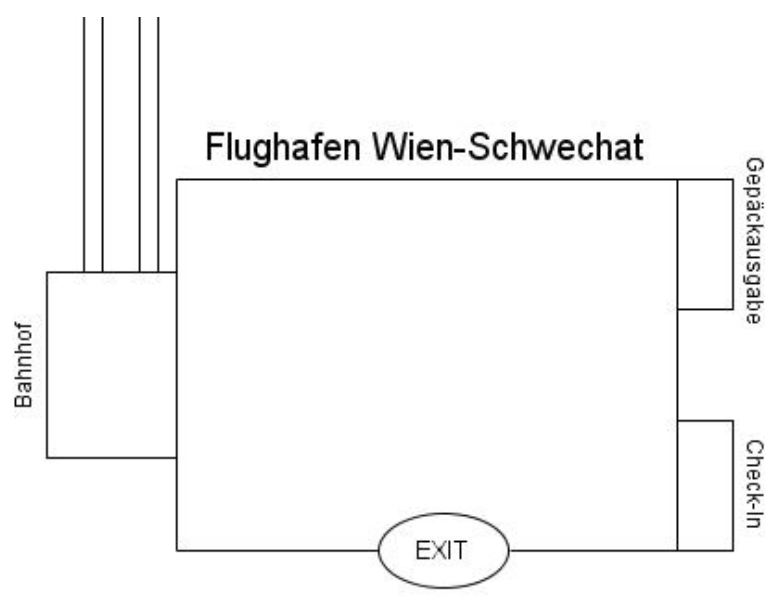

Figure 1: Simplified model of the Vienna International Airport used in the simulation. 'Bahnhof' stands for railway station and 'Gepäckausgabe' means baggage claim area.

In addition there are two graphics that illustrate the expenses, income and profit of the railway companies. Another dia gram illustrates pr oportionately how passengers arrive at or leave from the airport.

\section{The Agents}

To illustrate the decision making and rules of the agents, their possible activities are illustrated in the following.

\subsection{Incoming passengers}

In Figure 2 the process of an incom ing passenger i $\mathrm{s}$ shown. An incom ing agent is created at the ba ggage claim area of the $\mathrm{m}$ odel accord ing to the actual flight plan. Afterwards it is decided probabilistically (according to the modulations the us er made before the simulation started) if he is travelling only with hand luggage, if the passenger plans to take the train and in that case, if he is heading to the S-Bahn or the CAT.

Depending on these param eters the passenger is either waiting for his luggage at the bagga ge claim area, which would take half an hour on average, or is heading to the ai rport right away. If the passenger does not intend to go by train he/she is leaving the ai rport trough the EXIT. If the agent wants to use the S-Bahn, the simulation calculates his arrival tim e at the railway station and checks if there is a train connec tion. In that case the passenger starts to walk to the railway station.
As soon as a $\mathrm{n}$-Bahn representing agent arrives at the railway station the passenge $r$ gets the message that he is now able to enter the S-Bahn, which he is doing in the following as long as th ere is still place for the pas senger inside the train. Otherwise he has to wait for the next S-Bahn. If there is no train connection, the passenger has to look for another way of tra nsportation and is heading for the EXIT. Afterwards the agent is rem oved from the model.

CAT travelling passengers follow the same rules except that for $\mathrm{t}$ hem the CAT tim etable is checked for a connection and they are waiting for an CAT train.

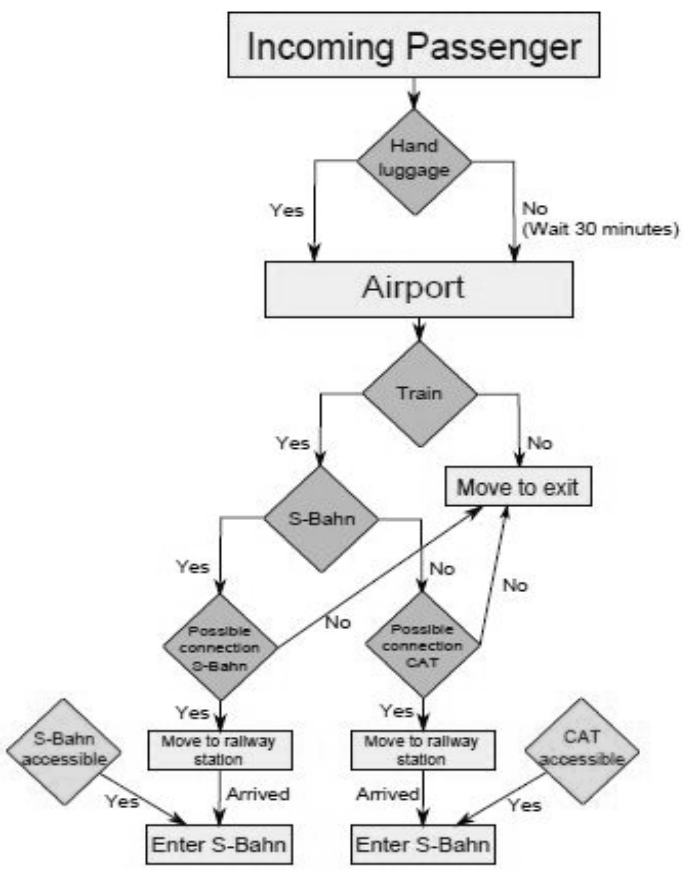

Figure 2: Decision making of a passenger who just exited the plane.

\subsection{Outgoing Passengers}

For an outgoing agent it is assum ed that he is going by train. Ot herwise he w ould have bee $\mathrm{n}$ cons tructed as a passenger who does not use a train for airport transportation in the first place. So an agent of the type outgoing passenger is either coming by S-Bahn or CAT, as shown in Figure 3. He is created at the railway station as soon as the best possible connection of his transportation type to get his flight reaches it.

Once the agent left the train he enters $t$ he airport right away and gets the order to $m$ ove to the check-in area. As s oon as he a rrived there he is wai ting for his flight to take off and then is removed. 


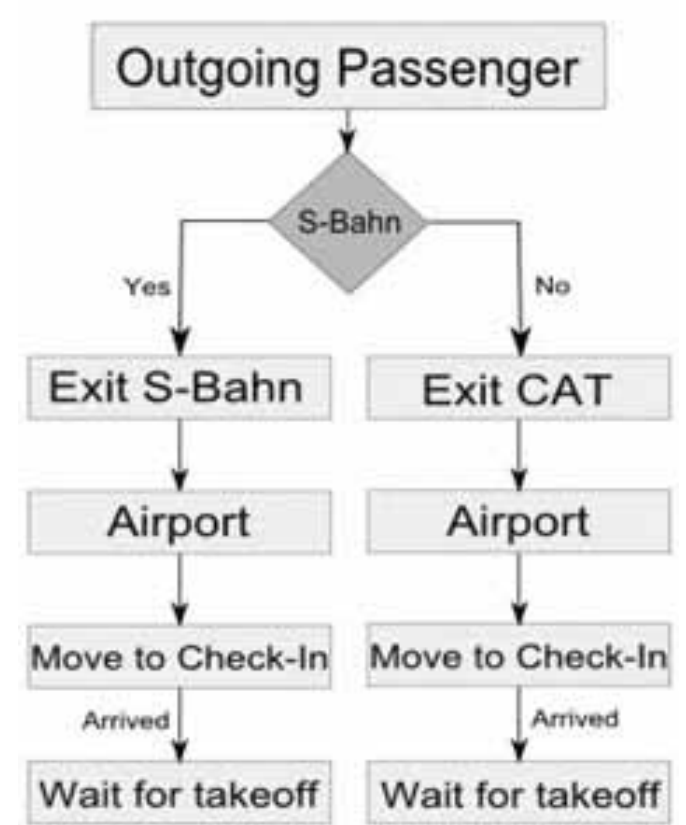

Figure 3: Decision making of a passenger who heads to the airport using train.

\subsection{Passengers who do not use a train for airport transportation}

This class is representing travelers who are not using the railway system and have therefore no direct input on the transportation companies profits. They are used to complete the amount of airplane users.

Therefore the decision making of these agent is very simple. They are created at the main exit and afterwards sent to the check-i $\mathrm{n}$ area, where t hey are waiting for their flight to takeoff to be removed from the simulation afterwards.So this agent type is more or less a si mplification of the outgoing passenger classes.

\subsection{Incoming trains}

Every incoming train is created, according to the (eve ntually modified) timetable [2] \& [3], at the upper end of the rails in $t$ he model. Then the agent gets the order to move along $t$ he rails straight to the airports railway station, as show $\mathrm{n}$ in Figure 4. Once he arrived, tw o functions calc ulate for which outgoing passe ngers (economy and business) this train is the ideal connection to reach their plane.

All these pass engers are now created and behave as described in ch apter 2.2 as lo ng as th e capacity of the train is not exceeded. Afterwards the train is rem oved from the simulation.

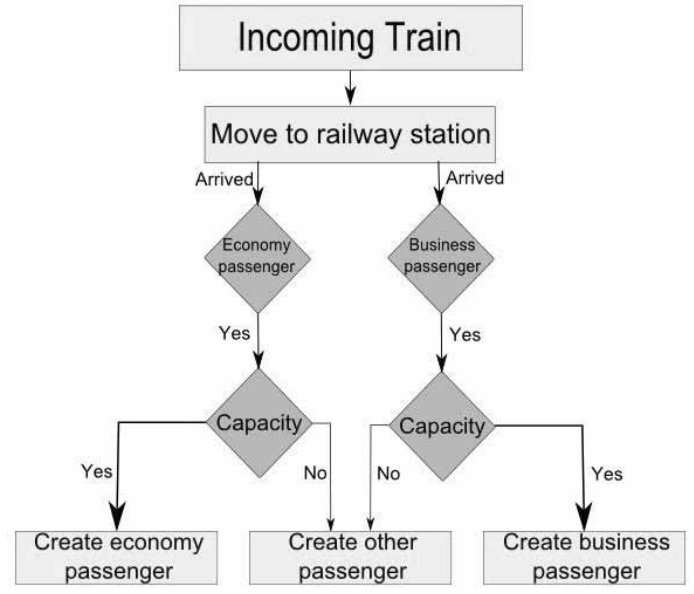

Figure 4: Decision making of an incoming train.

\subsection{Outgoing trains}

Every outgoing train is creat ed according to the tim etable [2] \& [3], directly at the airports railway station.

Once create $d$ he sends a message to the incom ing passengers wa iting at the railway station for his trai $\mathrm{n}$ type (so either S-Bahn or C AT), that they are now able to enter the train. As long as the capacity of the train is not exceeded these travelers are removed from the simulation like described above in chapter 2.1. After the train waited for 3 minutes in the railway station, he is sent to the edge of the visualization along $t$ he rail ways. Once reaching border the agent is removed from the simulation.

\section{Results}

Since $t$ his $m$ odel has various pa rameters that ca $n$ be changed by the user, the re is also a high am ount different scenarios. For that reason there are only a few interesting scenarios presented in the following.

In the tables S-Bahn is abbreviated with $\mathrm{SB}$, economy travelers with EC and business travelers with $\mathrm{BU}$. In both scenari os the ticket prices are set with $4,4 €$ for travelling with the S-Bahn and $12 €$ for the CAT.

\subsection{Scenario 1: Additional trains at peak hours}

In Scenario 1 most parameters remain unchanged during the different runs. This scenario analyzes if the S-Bahn could increase its profit and/or the am ount of trans ported passengers.

Table $1 \mathrm{~s}$ hows, that $\mathrm{S}$-Bahn profits decrease in all runs with addi tional trains. So with the gi ven working expenses and $t$ icket prices it is not profitable to exte nd the timetable at the chosen intervals. 
But if the amount of transported passengers is considered, it is obvious, that especially in the night hours the am ount of trans ported passengers increases significantly. It might be possible that the usage of trains in the night hours could be profitable with an increased ticket price and/or reduced working expanses.

The profit and passenger chances of the CAT are uninfluenced and within the probability variation.

\begin{tabular}{|c|c|c|c|c|}
\hline & Run 1 & Run 2 & Run 3 & Run 4 \\
\hline Train user EC & $70 \%$ & $70 \%$ & $70 \%$ & $70 \%$ \\
\hline SB user EC & $80 \%$ & $80 \%$ & $80 \%$ & $80 \%$ \\
\hline $\begin{array}{l}\text { Only hand } \\
\text { luggage EC }\end{array}$ & $25 \%$ & $25 \%$ & $25 \%$ & $25 \%$ \\
\hline Train user BU & $35 \%$ & $35 \%$ & $35 \%$ & $35 \%$ \\
\hline SB user BU & $45 \%$ & $45 \%$ & $45 \%$ & $45 \%$ \\
\hline $\begin{array}{l}\text { Only hand } \\
\text { luggage BU }\end{array}$ & $75 \%$ & $75 \%$ & $75 \%$ & $75 \%$ \\
\hline $\begin{array}{l}\text { Working ex- } \\
\text { penses per SB }\end{array}$ & 1250 & 1250 & 1250 & 1250 \\
\hline Capacity SB & 500 & 500 & 500 & 500 \\
\hline Capacity CAT & 500 & 500 & 500 & 500 \\
\hline $\begin{array}{l}\text { Additional SB } \\
\text { amount }\end{array}$ & 0 & 3 & 2 & 2 \\
\hline Add. SB time & - & $14-18 \mathrm{~h}$ & $6-10 \mathrm{~h}$ & $1-6 \mathrm{~h}$ \\
\hline Profit SB in $€$ & $19.074,56$ & $12.131,60$ & $15.357,60$ & $16.169,68$ \\
\hline Profit CAT in $€$ & $58.262,80$ & $58.423,20$ & $57.962,40$ & $57.928,80$ \\
\hline Passengers SB & 27.062 & 27.241 & 27.354 & 27.537 \\
\hline Passeng. CAT & 13.855 & 13.869 & 13.830 & 13.827 \\
\hline
\end{tabular}

Table 1: Scenario 1. Most parameters remain unchanged during the different run. The only differences are extensions of the S-Bahn timetable during different intervals.

Analyzing the results of Table 2, it is obvious that even the use of 16 more trains still extends the com pany's profit. $\mathrm{B}$ ut it $\mathrm{h}$ as to be co nsidered th at in $\mathrm{Ru} \mathrm{n} 3$ the amount of tra nsported passengers is $t$ he highest although no $f$ urther trains ha ve bee $n$ used. Therefore an increase of the capacity could be the best solution of this scenario if $\mathrm{t}$ he working e xpenses c ould be re duced. Especially if it is not possible to use 16 trains additionally Run 3 is definitely the best option to choose, since 8 more trains with less capacity in Run 2 offer less profit.

The big loss of the CAT c ompany is a conse quence of the big reduction of its users in this scenario.

\subsection{Scenario 2: Handling of increased use of the S-Bahn}

In the second scenario a different initial position is taken. It is supposed, that nearly all (90\%) of the travelers are usi ng the S-Bahn. So this scena rio analyzes the different opportunities of the S-Bahn operator to handle such an increased demand.

\begin{tabular}{|c|c|c|c|c|}
\hline & Run 1 & Run 2 & Run 3 & Run 4 \\
\hline Train user EC & $90 \%$ & $90 \%$ & $90 \%$ & $90 \%$ \\
\hline SB user EC & $90 \%$ & $90 \%$ & $90 \%$ & $90 \%$ \\
\hline $\begin{array}{l}\text { Only hand } \\
\text { luggage EC }\end{array}$ & $25 \%$ & $25 \%$ & $25 \%$ & $25 \%$ \\
\hline Train user BU & $90 \%$ & $90 \%$ & $90 \%$ & $90 \%$ \\
\hline SB user BU & $90 \%$ & $90 \%$ & $90 \%$ & $90 \%$ \\
\hline $\begin{array}{l}\text { Only hand } \\
\text { luggage BU }\end{array}$ & $75 \%$ & $75 \%$ & $75 \%$ & $75 \%$ \\
\hline $\begin{array}{l}\text { Working ex- } \\
\text { penses per SB }\end{array}$ & 1250 & 1250 & 1900 & 1250 \\
\hline $\begin{array}{l}\text { Working exp- } \\
\text { enses per CAT }\end{array}$ & 1500 & 1500 & 1500 & 1500 \\
\hline Capacity SB & 500 & 500 & 750 & 500 \\
\hline Capacity CAT & 500 & 500 & 500 & 500 \\
\hline $\begin{array}{l}\text { Additional SB } \\
\text { amount }\end{array}$ & 0 & 8 & 0 & 16 \\
\hline $\begin{array}{l}\text { Additional SB } \\
\text { time }\end{array}$ & - & $6-23 h$ & - & $4-24$ \\
\hline Profit SB in $€$ & $51.055,52$ & $59.294,72$ & $60.893,12$ & $62.990,88$ \\
\hline Profit CAT in $€$ & $-19.694,4$ & $-19.557,6$ & $-18.477,6$ & $-19.000,8$ \\
\hline Passengers SB & 34.331 & 40.749 & 48.385 & 45.850 \\
\hline $\begin{array}{l}\text { Passengers } \\
\text { CAT }\end{array}$ & 7.359 & 7.370 & 7.460 & 7.417 \\
\hline
\end{tabular}

Table 2: Scenario 2. Most parameters remain unchanged during the different run. The only differences are extensions of the S-Bahn timetable during different intervals in run 2 and 4 and higher working expenses in run 3.

\section{References}

[1] www.viennaairport.com/unternehmen/flughafen\_wien\ $\mathrm{ag} /$ facts $\backslash \backslash$ figures $\backslash$ fwag $\backslash$ gruppe, 24.8.2014.

[2] www.viennaairport.com/passagiere/anreise \_ _parken/sbahn, 25.08.2014.

[3] www.viennaairport.com/passagiere/anreise\\ $\mathrm{y} \backslash$ airport $\backslash$ train $\backslash$ cat, 25.08.2014. 